\title{
Biological effects different diameters of Tussah silk fibroin nanofibers on olfactory ensheathing cells
}

\author{
PENG WU $^{1 *}$, PENG ZHANG $^{1 *}$, HANJIANG ZHENG $^{2 *}$, BAOQI ZUO $^{3}$, XIAOFENG DUAN $^{2}$, \\ JUNJUN CHEN $^{2}$, XINHONG WANG $^{1}$ and YIXIN SHEN ${ }^{1}$ \\ ${ }^{1}$ Department of Orthopedics, The Second Affiliated Hospital of Soochow University, Suzhou, Jiangsu 215004; \\ ${ }^{2}$ Department of Orthopedics, The Second Hospital of Jingzhou, Jingzhou, Hubei 434000; \\ ${ }^{3}$ National Engineering Laboratory for Modern Silk, College of Textile and Clothing Engineering, \\ Soochow University, Suzhou, Jiangsu 215004, P.R. China
}

Received June 4, 2018; Accepted September 13, 2018

DOI: $10.3892 /$ etm.2018.6933

\begin{abstract}
Transplantation of olfactory ensheathing cells (OECs) has potential for treating spinal cord and brain injury. However, they are void of an extracellular matrix to support cell growth and migration. Engineering of tissue to mimic the extracellular matrix is a potential solution for neural repair. Tussah silk fibroin (TSF) has good biocompatibility and an Arg-Gly-Asp tripeptide sequence. A small number of studies have assessed the effect of the diameter of TSF nanofibers on cell adhesion, growth and migration. In the present study, TSF nanofibers with a diameter of 400 and $1,200 \mathrm{~nm}$ were prepared using electrospinning technology; these were then used as scaffolds for OECs. The structure and morphology of the TSF nanofibers were characterized by scanning electron microscopy (SEM) and Fourier-transform infrared spectroscopy. An inverted-phase contrast microscope and SEM were used to observe the morphology of OECs on the TSF nanofibers. The effect on the adhesion of the cells was observed following crystal violet staining. The phenotype of the cells and the maximum axon length on the scaffolds were evaluated by immunostaining for nerve growth factor receptor p75. Cell proliferation and viability were assessed by an MTT assay and a Live/Dead reagent kit. The migration efficiency of OECs was observed using live-cell microscopy. The results indicated that a 400-nm TSF fiber scaffold was more conducive to OEC adhesion, growth and migration compared with a 1,200-nm TSF scaffold. The phenotype of the OECs was normal, and no difference in OEC phenotype was observe when comparing
\end{abstract}

Correspondence to: Professor Yixin Shen, Department of Orthopedics, The Second Affiliated Hospital of Soochow University, 1055 Sanxiang Road, Suzhou, Jiangsu 215004, P.R. China E-mail: 476269142@qq.com

\section{${ }^{*}$ Contributed equally}

Key words: olfactory ensheathing cells, Tussah silk fibroin, fiber diameter, tissue engineering those on TSF nanofibers to those on PLL. The present study may provide guidance regarding the preparation of tissue-engineered materials for neural repair.

\section{Introduction}

Olfactory ensheathing cells (OECs) have an important role as seed cells in central nervous system (CNS) repair (1-3). OECs secrete a variety of neurotrophic factors, including nerve growth factors, as well as extracellular matrix molecules, to improve the microenvironment after nerve injury, reduce glial scarring and prevent neuronal apoptosis (4). Previous studies using animal models have also reported that OEC transplantation significantly promoted nerve fiber regeneration and partial functional recovery (5).

However, at present, the efficacy of cell transplants in repairing the CNS is not ideal as inflammatory substances and glial scar formation has been demonstrated to inhibit the secretion of extracellular matrix components and cell scaffolds (6). In recent years, promising tissue-engineered biomaterial scaffolds have been demonstrated to have the capacity to improve the repair of CNS injury. The ideal biomaterials should have biodegradability, biocompatibility, excellent mechanical properties and flexibility $(7,8)$. Natural biodegradable materials include chitosan, polypeptide hydrogel, poly L-lactic acid (PLL), chitosan/polyethylene stents and non-cellular scaffolds, which have been considered for the repair of nerve damage (9-11). Our group has been working on natural Tussah silk fibroin (TSF) biomedical materials for numerous years (12). TSF is a natural protein with a polymer structure. Its amino acid composition is characterized by a large number of arginine-glycine-aspartic acid (RGD) tripeptide sequences. This RGD tripeptide sequence structure is known to facilitate cell adhesion. TSF also has good biocompatibility, with no toxic effects on cells and organisms, and a low likelihood of inflammatory reaction or immune rejection (13-16).

In recent years, the use of this electrospinning technology has led to great progress in the preparation of tissue-engineered materials. The diameter, structure distribution, molecular conformation and crystallinity of TSF may be controlled using electrospinning technology (17). When the fiber diameter is 
decreased from microns to nanometers, the material properties are improved accordingly.

A previous study by our group indicated that TSF scaffolds prepared by electrostatic spinning have good biocompatibility with OECs and may support their growth and migration (12). However, the study also suggested that the diameter of nanoscale fibers affects the biological effects of OECs. Previous studies have demonstrated that the diameter of electrospun nanofibers has a significant effect on cell behavior (18-20). In one study, fibers with a diameter of 400 and 1,200 $\mathrm{nm}$ were prepared for evaluating their effect on cell behavior (21), and the results suggested that the diameter of the scaffold had a marked impact on neural cell behavior, with a significant increase in the cell-spreading area observed on 400-nm silk fibroin (SF). A significantly enhanced migration efficiency of astrocytes grown on SF scaffolds was demonstrated, which highlighted the effects of SF nanofibers to enhance cell migration. As it was indicated that the diameter of SF nanofibers may be an important factor in the construction of biomimetic microenvironments suitable for cell growth, the present study aimed to assess the ideal diameter of TSF as a tissue engineering scaffold material.

\section{Materials and methods}

Materials and sample preparation. TSF nanofibers were prepared as previously reported (22). In brief, TSF fibers were boiled in $0.5 \%$ (w/w) $\mathrm{Na}_{2} \mathrm{CO}_{3}$ aqueous solution for $30 \mathrm{~min}$ twice for degumming, followed by thorough rinsing with sufficient deionized water to remove the glue-like sericin. The degummed TSF fibers were dissolved in $16 \mathrm{M}$ lithium thiocyanate solution and the mixture was heated with hotplate stirrers at $50^{\circ} \mathrm{C}$ for $1 \mathrm{~h}$, followed by dialysis with cellulose tubular membranes in distilled water for 3 days (molecular weight cut-off, $8,000-14,000 \mathrm{kDa}$ ). A TSF film was prepared by spreading the TSF solution onto a polyethylene plastic board and leaving it to dry at room temperature. The electrospinning solution was prepared by dissolving the TSF film in hexafluoroisopropanol with hotplate stirrers for 1 week at $25^{\circ} \mathrm{C}$. The spin solution was transferred to a $10-\mathrm{ml}$ syringe with an $18 \mathrm{G}$ needle. The flow rate was $0.5 \mathrm{ml} / \mathrm{h}$, the voltage was gradually increased to $16 \mathrm{kV}$ and the collection distance was $12 \mathrm{~cm}$. TSF nanofibers with diameters of 400 and 1,200 $\mathrm{nm}$ were generated using spin solutions with concentrations of 8 and $16 \mathrm{wt} \%$, respectively. The as-spun TSF nanofibers were immersed in $75 \%$ (v/v) ethanol/water for 30 min to induce a structural change, and then dried at room temperature for $24 \mathrm{~h}$. Finally, the TSF nanofibers were X-rayed prior to use. X-ray diffraction experiments were measured on X'Pert Pro MPD (PANalytical B.V., Almelo, Netherlands) in transmittance mode to investigate the crystalline structure of samples at a wavelength of $0.154 \mathrm{~nm}$. Lastly, the intensity of the incident beam, the sample absorption and the background were corrected for changes (23).

Material characterization. The samples were cut into squares of $1 \mathrm{~mm}^{2}$ and fixed on copper chips. After spraying with gold, they were observed using a scanning electron microscope (SEM) $(23,24)$. In order to calculate the diameter of the nanofibers, SEM images of $>100$ independent fibers were analyzed by ImageJ software (version 1.47; National Institutes of Health, Bethesda, MD, USA). Fourier Transform Infrared Spectroscopy (FTIR) is a powerful and commonly used tool for secondary structure analysis; the conformational changes and secondary structure of TSF nanofibers after ethanol treatment were determined by FTIR $(24,25)$.

In vitro primary cultured OECs on TSF scaffolds. All animal experiments of the present study were approved by the Ethics Committee of the Second Affiliated Hospital of Soochow University (Suzhou, China) and performed in accordance with the Guidelines for the Welfare of Animals of Soochow University (Suzhou, China) (12) as well as the National Institute of Health's Guide for the Care and Use of Laboratory Animals (26). Primary cultures of OECs were prepared from 30 male Sprague Dawley rats (weight, 100-150 g; age, 4-5 weeks; Experimental Animal Center of Soochow University) as reported previously (12). The culture medium for OECs consisted of Dulbecco's modified Eagle's medium (DMEM)/F-12 (Gibco; Thermo Fisher Scientific, Inc., Waltham, MA, USA) with $10 \%$ fetal bovine serum (FBS; Gibco; Thermo Fisher Scientific, Inc.), $1 \%$ glutamine (Sigma-Aldrich; Merck KGaA, Darmstadt, Germany) and 2\% penicillin-streptomycin (Harbin Pharmaceutical Group Co., Ltd., Harbin, China). The culturing condition was as follows: $37^{\circ} \mathrm{C}$ in a humidified atmosphere containing $5 \% \mathrm{CO}_{2}$. After 10 days in culture, OECs were used for a biocompatibility evaluation with TSF nanofibers. The OECs were detached with $0.1 \%$ trypsin (Sigma-Aldrich; Merck KGaA) at $37^{\circ} \mathrm{C}$ for $10 \mathrm{~min}$, centrifuged at $157 \mathrm{x}$ g for $5 \mathrm{~min}$ and then resuspended. Subsequently, the OECs $\left(1.0 \times 10^{5}\right)$ were seeded on coverslips coated with 400-nm or 1,200-nm TSF fibers or PLL (Sigma-Aldrich; Merck KGaA) that had been pre-wetted with culture medium in 35-mm Petri dishes (Corning Inc., Corning, NY, USA), the dimensions of TSF fibers were 10x10x1 mm, the thickness was $1 \mathrm{~mm}$; PLL served as a positive control. The nanofibers were incubated in $1 \mathrm{ml}$ complete culture medium at $37^{\circ} \mathrm{C}$ for $30 \mathrm{~min}$ prior to seeding. Cell suspension $(1 \mathrm{ml})$ was placed on the fibers in each dish, and $1 \mathrm{ml}$ culture medium was added after $4 \mathrm{~h}$. The culture medium was changed every 3 days. After culture for 4 days, the samples were observed with an inverted phase-contrast microscope and SEM, using the same method of SEM as described above.

Immunofluorescence staining and quantitative analysis for OECs on TSF scaffolds. OECs were seeded on the TSF nanofibers or PLL-coated coverslips as described above, and their identity was confirmed by immunostaining. Cells on the fibers and PLL were fixed for $30 \mathrm{~min}$ at room temperature with $4 \%$ paraformaldehyde (Zhongde Chemical Products Trade Co., Ltd., Tianjin, China) and then blocked for 30 min in PBS containing 3\% bovine serum albumin (BSA), $0.2 \%$ Triton $\mathrm{X}-100$ and $0.02 \% \mathrm{NaN}_{3}$ (v/v) (all from Sigma-Aldrich; Merck KGaA). The cells were incubated with rabbit polyclonal anti-nerve growth factor receptor (NGFR) p75 (cat. no. BA0514-2; Wuhan Boster Biological Technology, Ltd., Wuhan, China), diluted to 1:200 in PBS, at $4^{\circ} \mathrm{C}$ overnight. Following three washes with PBS, cells were incubated with fluorescein isothiocyanate-conjugated goat anti-rabbit secondary antibodies (cat. no. BA1105; Wuhan Boster Biological Technology, Ltd.) diluted 1:70 in PBS for $1 \mathrm{~h}$ 
at room temperature. Following three washes with PBS, cell nuclei were stained with Hoechst 33258 diluted 1:100 in PBS at room temperature for $15 \mathrm{~min}$. Cover slips were washed with PBS, mounted with 50\% glycerin in PBS and imaged with an AF6000 fluorescence microscope (Leica Microsystems GmbH, Wetzlar, Germany).

To evaluate the growth of OECs on TSF nanofibers, the spreading area and the longest cellular process of OECs on TSF nanofibers were quantified at 1, 4 and 7 days. In brief, at least 10 individual cells from three randomly selected fields were measured with ImageJ 1.47 software on the basis of NGFR p75 immunostaining. At least five coverslips were included for each experimental group. Experiments were repeated three times.

Crystal violet staining for cell adhesion assays. The attachment test for OECs on TSF nanofibers was performed as previously described (27). In brief, $500 \mu \mathrm{l}$ OEC suspension ( $1 \times 10^{5}$ cells $\left./ \mathrm{ml}\right)$ was seeded into TSF nanofibers and a $24-w e l l$ PLL-coated plate. Plates were coated with PLL by adding $1 \mathrm{ml}$ $0.1 \% \mathrm{mg} / \mathrm{ml}$ PLL solution to each well at room temperature overnight. The PLL solution was aspirated and the plates were left to dry on a clean bench. OECs were incubated for 1 or $3 \mathrm{~h}$ in an atmosphere of $5 \% \mathrm{CO}_{2}$ at $37^{\circ} \mathrm{C}$. The loose and unadhered cells were removed. The wells were gently washed twice with PBS. The adherent cells were fixed with $15 \%$ formalin in PBS for $15 \mathrm{~min}$. Once the fixation was completed, the wells were washed twice with PBS and stained with $0.05 \mathrm{~g} / \mathrm{ml}$ crystal violet at $37^{\circ} \mathrm{C}$ for $15 \mathrm{~min}$. In each well, the number of cells was counted in five microscopic fields (magnification, x200) and images were captured under an Olympus microscope (Olympus Corp., Tokyo, Japan).

MTT cell proliferation assay. The proliferation of OECs on TSF and PLL was examined at 1,4, 7 and 10 days. At each time-point, $20 \mu 1$ MTT (Sigma-Aldrich; Merck KGaA) dissolved in PBS at $5 \mathrm{mg} / \mathrm{ml}$ was added to each well, followed by incubation at $37^{\circ} \mathrm{C}$ for $4 \mathrm{~h}$. Then, the medium was discarded and $150 \mu \mathrm{l}$ dimethyl sulfoxide (Sigma-Aldrich; Merck KGaA) was added to each well to dissolve the dark blue crystals with agitation for $10 \mathrm{~min}$. The absorbance was measured at $490 \mathrm{~nm}$ with a microplate reader (iMark $^{\text {TM }}$ Microplate Absorbance Reader-168-1130; Bio-Rad Laboratories, Inc., Hercules, CA, USA).

Live/Dead Kit cell viability analysis. The Live/Dead viability/cytotoxicity kit (cat. no. L3224; Invitrogen; Thermo Fisher Scientific, Inc.), including $0.5 \mathrm{mM}$ calcein AM and $0.5 \mathrm{mM}$ ethidium homodimer-1 (Ethd-1) dissolved in $1 \mathrm{ml}$ $\mathrm{DMEM} / \mathrm{F}-12$, was used for quantitative cell viability analysis after 6 days of culture on PLL or TSF scaffolds in a 6-well plate. In live cells, calcein displays bright green fluorescence, while in dead cells, Ethd-1 binding to nucleic acids results in red fluorescence. Live/dead reagent was added to cells, followed by incubation at $37^{\circ} \mathrm{C}$ for $30 \mathrm{~min}$ and subsequent washing with PBS twice and observation under a fluorescence microscope. In each well, 3,000 cells were counted from randomly selected fields.

Live-cell imaging for migration assay. The migration of OECs on TSF nanofibers was assayed by timelapse video

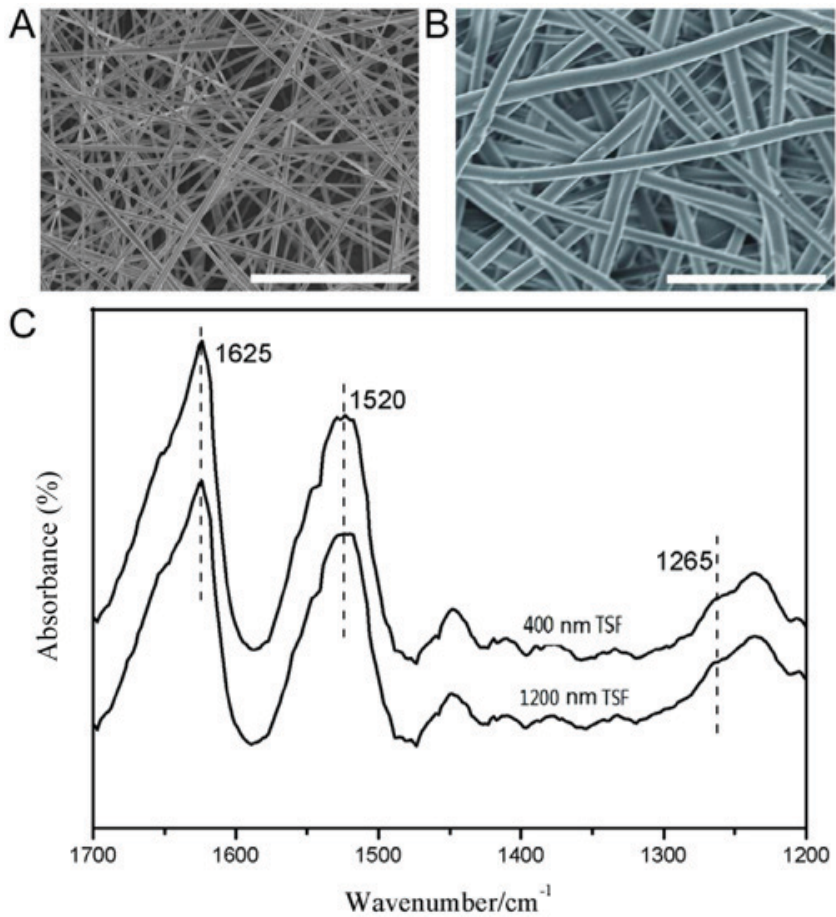

Figure 1. Morphology and structure of TSF. Scanning electron microscope images of TSF with a diameter of (A) $400 \pm 44 \mathrm{~nm}$ and (B) $1,200 \pm 95 \mathrm{~nm}$ (scale bar, $10 \mu \mathrm{m})$. (C) The infrared spectrum absorption peaks of the TSF were $1,625 \mathrm{~cm}^{-1}$ (amide I), 1,520 $\mathrm{cm}^{-1}$ (amide II) and 1,265 $\mathrm{cm}^{-1}$ (amide III). TSF, Tussah silk fibroin.

microscopy. An environmental chamber was used to maintain optimal growth conditions for OECs at $37^{\circ} \mathrm{C}$. In brief, coverslips with cells were loaded and observed every 5 min using a 10X objective under a Leica DMI 6000 B microscope for a period of $400 \mathrm{~min}$. The forward migration index (FMI) was calculated as the ratio of forward progress (the net distance a cell progressed) to the total path length (total distance a cell traveled through the field).

Statistical analysis. Values are expressed as the mean \pm standard error of the mean. Statistical analysis was performed using analysis of variance followed by a Dunn-Bonferroni post-hoc test for multiple group comparisons using GraphPad Prism 6.0 software (GraphPad Software, Inc., La Jolla, CA, USA). P<0.05 was considered to indicate a statistically significant difference.

\section{Results}

Morphology and structure of TSF. In order to assess the role of the nanofiber diameter in regulating cell behavior, TSF nanofibers of different diameter were prepared. As presented in Fig. 1A and B, the diameters of the two types of TSF

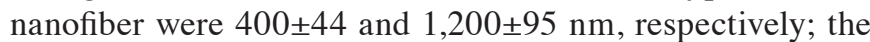
nanofibers exhibited a smooth surface with micro-sized pores to allow for cell proliferation and penetration. Although native silk fibroin is stable in water, the regenerated silk material is usually post-treated with a solvent to achieve stability. In the present study, $75 \%$ ethanol was employed to treat as-spun TSF nanofibers and induce this structural change.

As presented in Fig. 1C, the FTIR spectra of TSF nanofibers exhibited absorption bands at $1,625 \mathrm{~cm}^{-1}$ (amide I), 

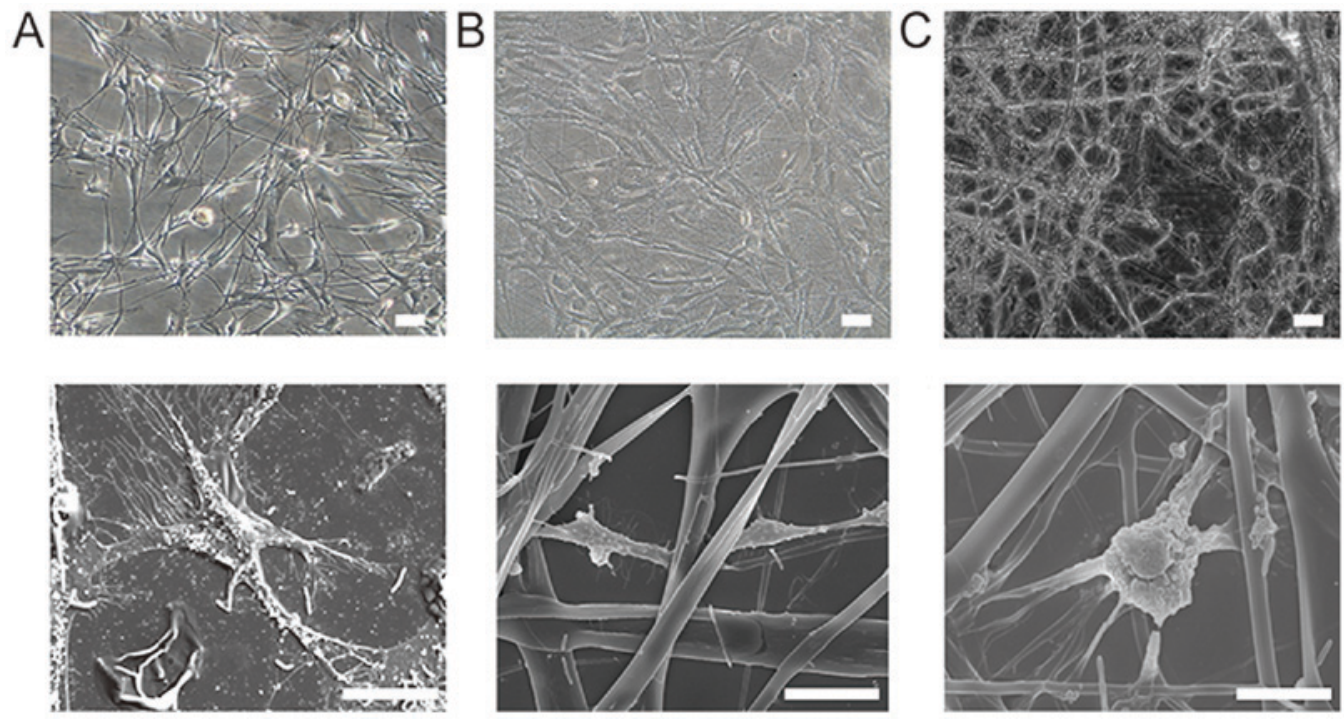

Figure 2. Growth of OECs on vehicle or TSF. Morphology and growth of OECs on (A) poly-L-lysine, (B) 400-nm TSF and (C) 1,200-nm TSF nanofibers at 4 days (scale bar, $250 \mu \mathrm{m}$ in upper panel and $50 \mu \mathrm{m}$ in lower panel). TSF, Tussah silk fibroin; OECs, olfactory ensheathing cells.

$1,520 \mathrm{~cm}^{-1}$ (amide II) and $1,265 \mathrm{~cm}^{-1}$ (amide III), attributed to a $\beta$-sheet structure. The crystalline $\beta$-sheet structure is the basis for the water stability and strength of the TSF nanofibers. Thus, water-stable TSF nanofibers with different diameters were successfully prepared.

Morphology and structure of OECs on TSF. An inverted-phase contrast microscope was used to observe the OECs cultured on PLL and TSF (400 and 1,200 nm) after 4 days (Fig. 2A-C). Most OECs presented with a bipolar or tripolar morphology, with excellent refraction. The cells on PLL were connected through cell processes. The OECs on TSF followed the fiber direction, and adjacent cells formed connections through neurites. As presented in Fig. 2D and E, SEM revealed that OECs grew on the surface and pores of the TSF microfibers after 4 days of culture. The surfaces of the cells produced different cellular processes, crossing the microporous surface to form intercellular connections. In addition, extracellular matrix production was observed in gaps in the material. Most of the OECs on the 400-nm TSF displayed flat cell bodies and elongated protuberances, with the cells tightly linked. The cellular connections of OECs on 1,200-nm TSF were fewer than those on 400-nm TSF.

Immunostaining and growth parameters of OECs on TSF. NGFR p75 staining indicated that OECs on TSF retained their phenotype. Hoechst 33258 staining revealed that the nuclei of the OECs were round or oval; no chromatin condensation or apoptotic body formation was observed and the staining was uniform, indicating that there were no obvious apoptotic phenomena of OECs grown on TSF nanofibers of either diameter.

As presented in Fig. 3, the difference in the area of OEC spreading on the two types of TSF nanofiber after 1 day was relatively small $\left(0.9-1.5 \times 10^{3} \mu \mathrm{m}^{2}\right)$. After 4 days, the area of cell spreading on $400 \mathrm{~nm}$ TSF fibers reached $3.8 \times 10^{3} \mu \mathrm{m}^{2}$, which was significantly higher than that on $1,200 \mathrm{~nm}$ TSF $\left(3 \times 10^{3} \mu \mathrm{m}^{2} ; \mathrm{P}<0.05\right)$. Significant differences in the spreading area between the OECs grown on PLL or $400 \mathrm{~nm}$ TSF fibers and the 1,200 nm TSF fibers were obtained at 7 days $(\mathrm{P}<0.05)$. Quantitative analysis also indicated that the maximum process length of OECs on $400 \mathrm{~nm}$ TSF fibers was significantly longer than that of OECs on 1,200 nm fibers at 4 and 7 days $(\mathrm{P}<0.05)$.

Cell adhesion of OECs on TSF. The cell adhesion on $400 \mathrm{~nm}$ TSF was greater than that on PLL or 1,200 nm TSF $(\mathrm{P}<0.05)$. The cell adhesion on PLL was the lowest (Fig. 4). This may be due to TSF containing more RGD sequences.

Proliferation and viability of OECs on TSF. As presented in Fig. 5A-C, the morphology of OECs on TSF was normal. The majority of the cells were distributed along the fiber and evenly distributed. According to an MTT assay (Fig. 5D), the absorbance value in the 1,200 nm TSF group was significantly less than that in the $400 \mathrm{~nm}$ TSF and PLL groups at 4 days (both $\mathrm{P}<0.05$ ), and the absorbance value of the $1,200 \mathrm{~nm}$ TSF group was significantly less than that of the PLL group at 7 days $(\mathrm{P}<0.05)$. However, there were no differences between the groups at 1 and 10 days. These results indicate that, compared with PLL, TSF has good biocompatibility and did not induce any marked cytotoxicity on OECs.

The cell viability and death rates were not significantly different in the TSF groups (Fig. 5E). These results indicated that TSF nanofibers successfully supported the survival, growth and proliferation of OECs.

Cell migration of OECs on TSF. Cell migration was analyzed by single-cell trajectories. The starting point of each cell migration was standardized to the intersection point of the $\mathrm{X}$ - and Y-axes. OECs on PLL migrated in random directions, whereas those on 400- and 1,200-nm TSF moved along the fiber. In order to measure cell motility, the FMI was calculated and analyzed (Fig. 6). Quantitative analysis suggested that the FMI of OECs in the 400-nm TSF group was significantly higher than that in the PLL group $(\mathrm{P}<0.05)$. 


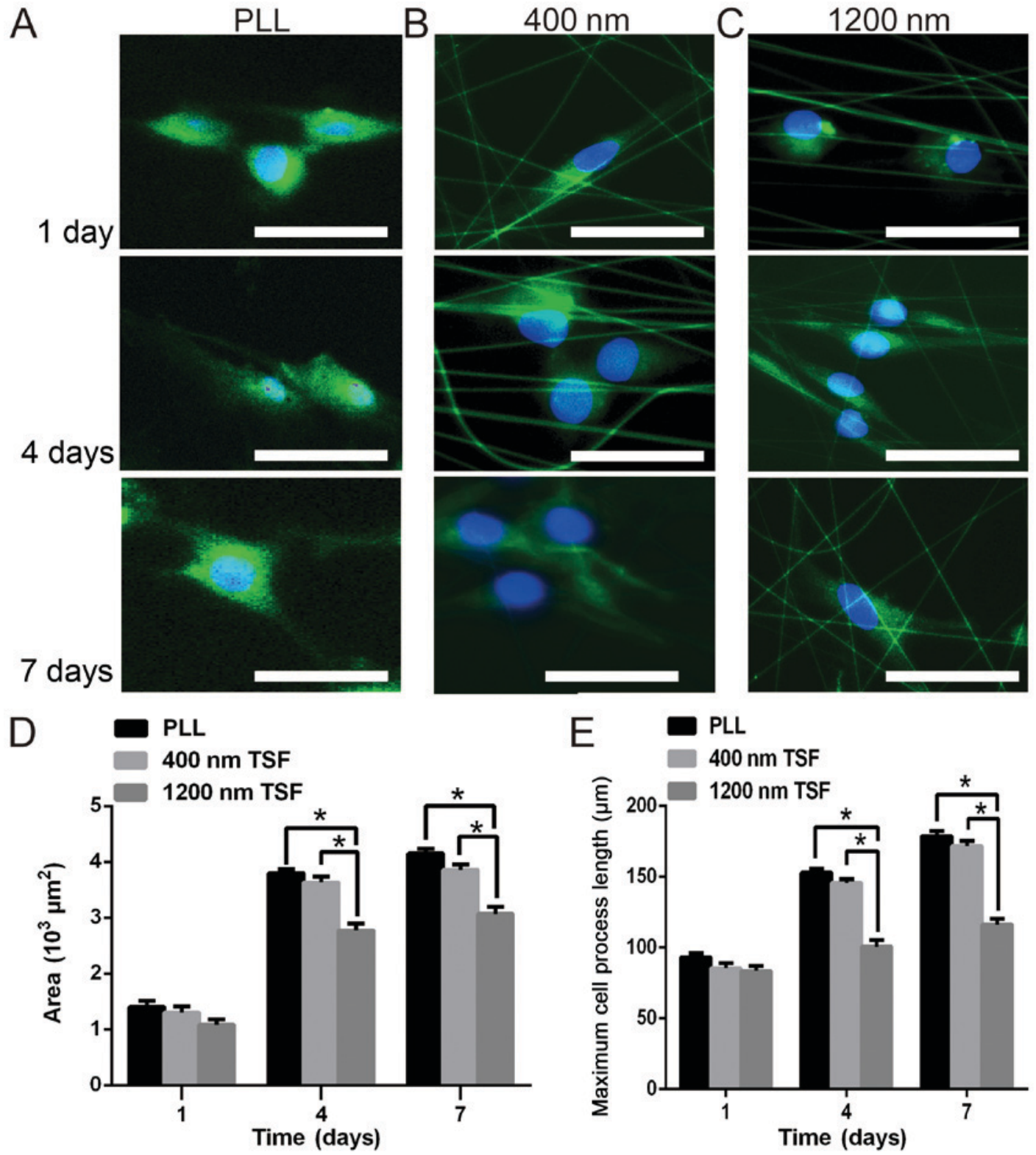

Figure 3. Effect of the TSF scaffold diameter on the growth and spread of OECs. Immunocytochemistry staining of OECs with anti-NGFR p75 antibodies (green) and Hoechst 33258 (blue). OECs were cultured on (A) PLL and (B and C) TSF nanofibers with a diameter of (B) $400 \mathrm{~nm}$ and (C) 1,200 nm, and were observed at 1,4 and 7 days (scale bar, $25 \mu \mathrm{m}$ ) using a fluorescence microscope. (D) The spreading area and (E) the longest process of OECS was quantified at 1,4 and 7 days. The area of OECs on the $400-\mathrm{nm}$ TSF fibers reached $3.8 \times 10^{3} \mu \mathrm{m}^{2}$, which was significantly higher than on $1,200-\mathrm{nm}$ TSF, which reached $3.0 \times 10^{3} \mu \mathrm{m}^{2}$. There were also significant differences in the spread area of cells between PLL fibers and 1,200 nm TSF fibers at 7 days. In addition, the longest process of OECs on 400-nm TSF was significantly longer than that of OECs on 1,200-nm TSF on days 4 and 7. "P<0.05. TSF, Tussah silk fibroin; OECs, olfactory ensheathing cells; PLL, poly-L-lysine.

\section{Discussion}

It has been verified that TSF has good biocompatibility, permeability and biodegradability, with a low inflammatory response and other favorable qualities $(28,29)$. TSF supports cell growth, proliferation and differentiation; in vivo studies have also reported that it facilitates tissue repair $(30,31)$. A further advantage of TSF is that it promotes cell adhesion and migration through the RGD tripeptide sequence, a biometric signal (32). It has been reported that TSF was beneficial for the adhesion and growth of fibroblasts and bone marrow mesenchymal stem cells in a mouse model $(33,34)$.

The present study indicates that the diameter of nanofibers has an important role in the arrangement and specific biological behavior of cells. OECs were observed to be well-aligned on 400-nm TSF, while cells were randomly arranged on 1,200-nm TSF. This result suggests that a smaller diameter $(400 \mathrm{~nm})$ of TSF nanofibers may promote cell alignment when compared with a larger diameter $(1,200 \mathrm{~nm})$. This result is similar that of a previous study by our group on OECs cultured on fabricated SF scaffolds of different diameters (35). The RGD tri-peptide sequence structure of TSF has been demonstrated to facilitate cell adhesion (13). TSF has also been shown to possess good biocompatibility with no toxic effects on cells and organisms, and a low likelihood of inflammatory reaction or immune rejection (15). Through the current study, it was speculated that a smaller diameter of TSF nanofibers is more similar to the microenvironment created by the natural extracellular matrix, 

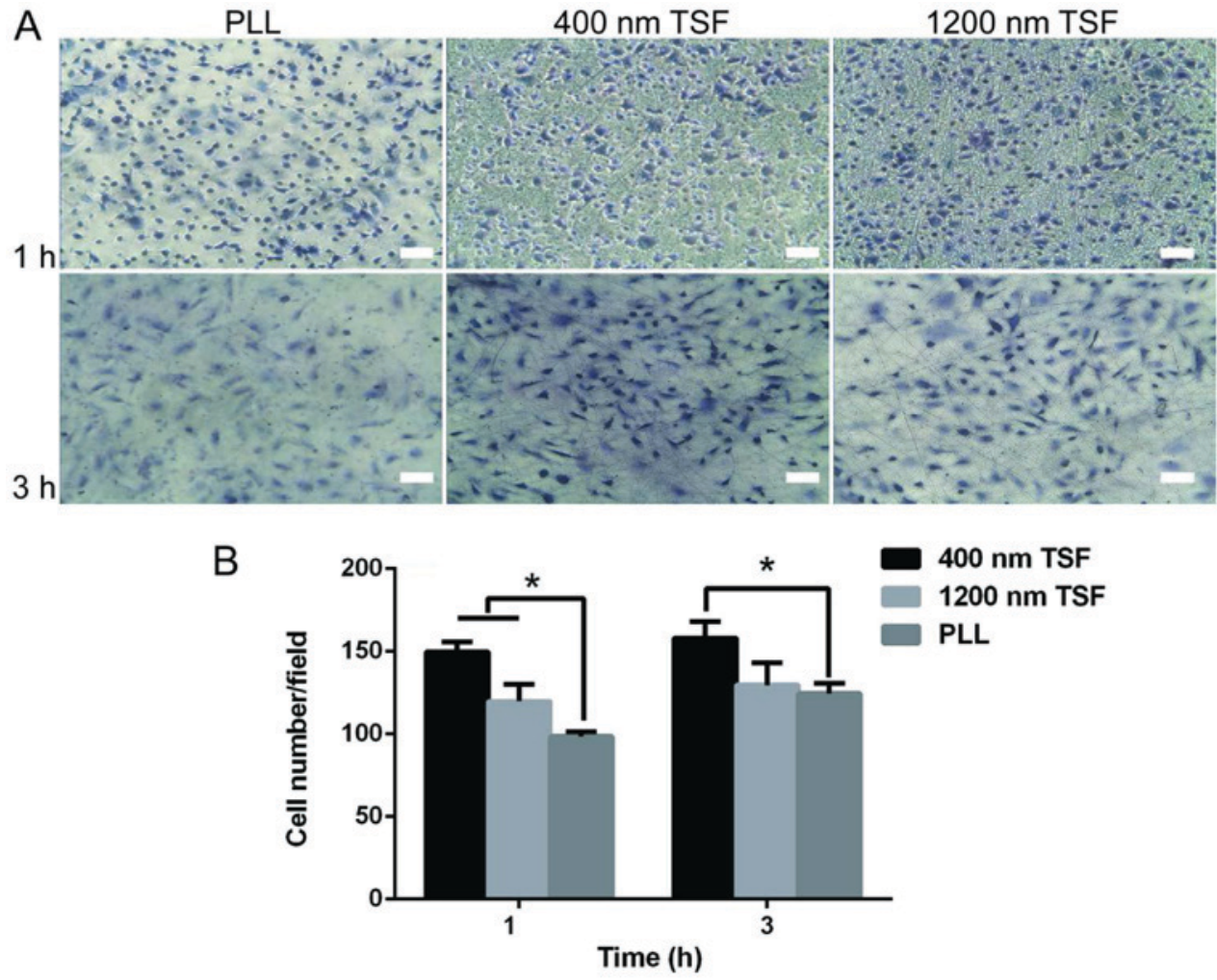

Figure 4. OEC adhesion performance. (A) Following culture for 1 or $3 \mathrm{~h}$, the morphology and adhesion of OECs on PLL, 400-nm TSF nanofibers and 1,200-nm TSF nanofibers were examined. (B) 400-nm TSF nanofibers exhibited significant advantages in adhesion compared with PLL or 1,200-nm TSF. PLL provided the least effective matrix. Scale bar, $100 \mu \mathrm{m}$; crystal violet staining. "P<0.05. TSF, Tussah silk fibroin; OECs, olfactory ensheathing cells; PLL, poly-L-lysine.

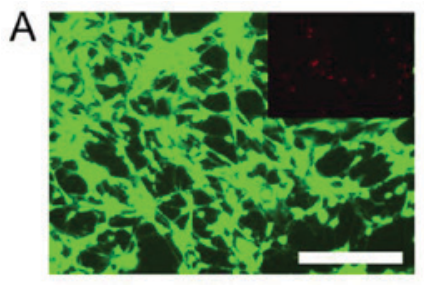

D

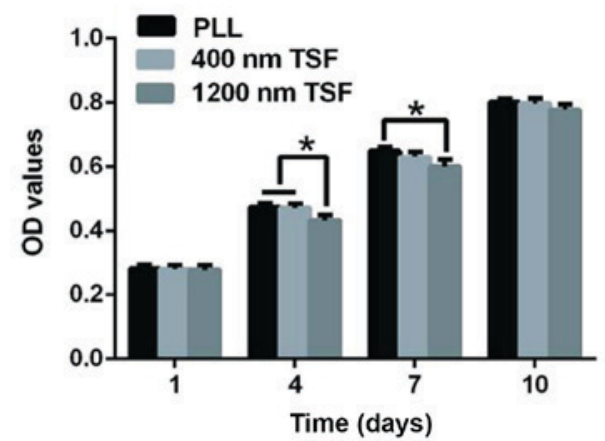

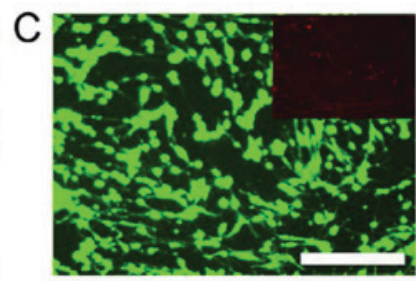

$\mathrm{E}$

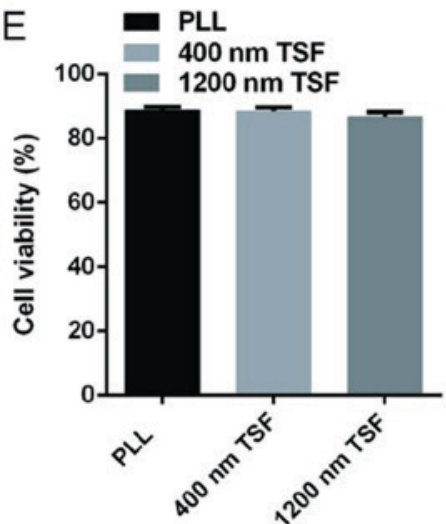

Figure 5. Effects of (A) PLL, (B) 400-nm TSF and (C) 1,200-nm TSF on OEC proliferation and viability. (D) After 4 days of culture, the absorbance value in the 1,200-nm TSF group was significantly lower than that in the 400-nm TSF or the PLL group, as well as the PLL group at 7 days. Scale bar, $250 \mu \mathrm{m}$. (E) Live/dead cell staining revealed no significant differences between the groups. " $\mathrm{P}<0.05$. TSF, Tussah silk fibroin; OECs, olfactory ensheathing cells; PLL, poly-L-lysine; OD, optical density.

which is suitable for cell survival and proliferation. However, the specific biochemical effects and directional guidance of TSF nanofibers, as well as the underlying mechanisms, still require further study.
Based on the above results, it may be speculated that the precise control of the direction of nanofibers may control the arrangement and directional migration of cells to promote the regeneration of axons and the repair of central nerve 
A PLL
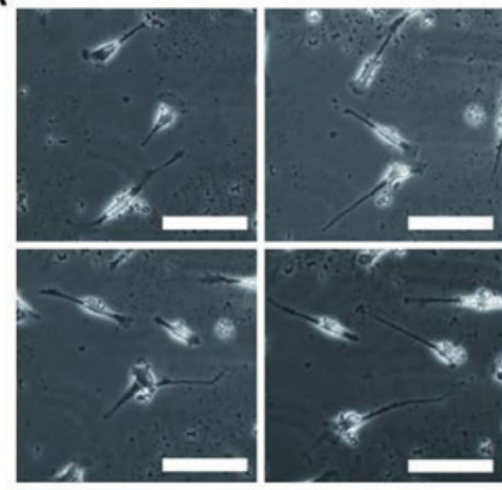

C $1200 \mathrm{~nm}$ TSF
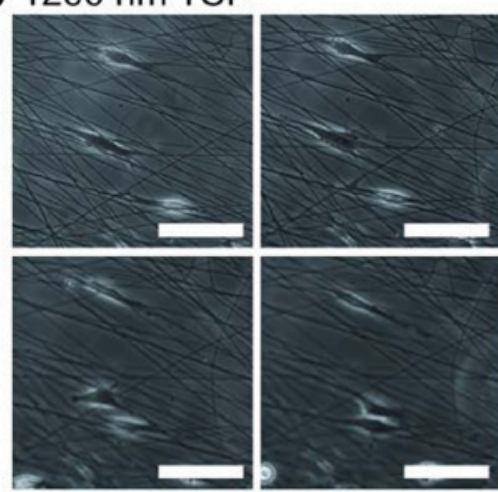
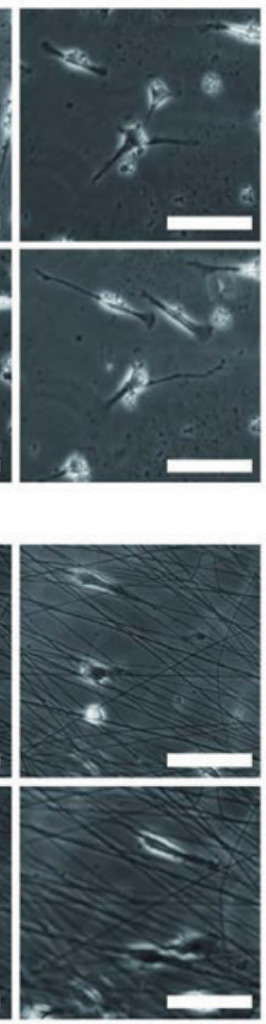
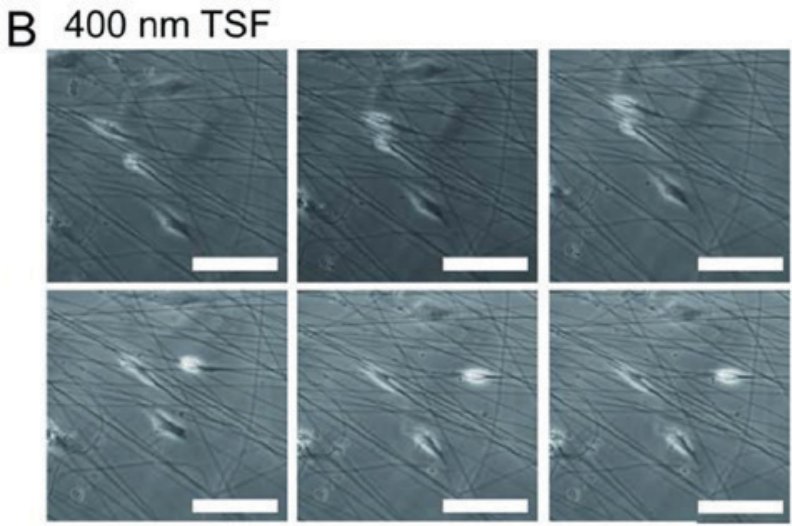

D

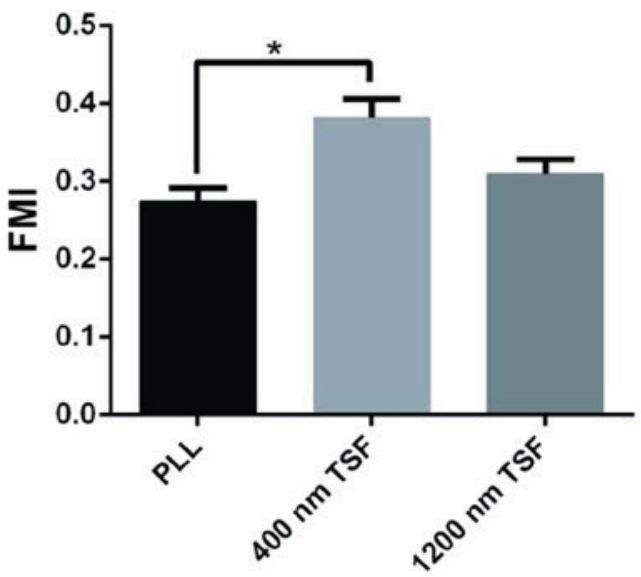

Figure 6. The FMI of OECs on (A) PLL, (B) 400-nm TSF and (C) 1,200-nm TSF was calculated. OECs on PLL migrated in random directions, whereas those on 400- and 1,200-nm TSF moved along the fibers. (D) The FMI in the 400-nm TSF group was significantly higher than that in the PLL group. Scale bar, $100 \mu \mathrm{m}$. "P<0.05. TSF, Tussah silk fibroin; OECs, olfactory ensheathing cells; PLL, poly-L-lysine; FMI, forward migration index.

injury. This may be facilitated by the application of physical or chemical stimuli, including electrical stimulation or growth factor release (36).

In conclusion, through electrospinning, a three-dimensional TSF scaffold material with a controllable diameter, smooth surface and uniform pore spacing was prepared. These TSF nanofibers do not affect the phenotype of OECs, and support their adhesion, migration, growth and proliferation. The performance of the 400-nm TSF fibers, including OEC adhesion, proliferation and migration, was improved relative to that of the 1,200-nm TSF fibers. This indicates that TSF nanofibers with a diameter of 400-nm may be a superior scaffold material for repairing nerve injury. However, the mechanisms of this effect require further study.

\section{Acknowledgements}

The authors would like to thank Professor Huanxiang Zhang (Department of Cell Biology, Jiangsu Key Laboratory of Stem Cell Research, Medical College of Soochow University, Suzhou, China) for the guidance provided during the experiment.

\section{Funding}

This work was supported by the National Natural Science Foundation of China (grant no. 81271723) and the Applied Basic Research Project of Suzhou (grant no. SYS201622).

\section{Availability of data and materials}

The analyzed data sets generated during the study are available from the corresponding author on reasonable request.

\section{Authors' contributions}

YS conceived and designed the experiments. PW, HZ and PZ performed the experiments and wrote the paper. XW collected data. XD and JC analyzed the data. BZ interpreted the results and revised the manuscript. All authors discussed and approved the final manuscript.

\section{Ethical approval and consent to participate}

All animal experiments of the present study were approved by the Ethics Committee of the Second Affiliated Hospital of Soochow University (Suzhou, China).

\section{Patient consent for publication}

Not applicable.

\section{Competing interests}

The authors declare that they have no competing interests regarding this study. 


\section{References}

1. Voronova AD, Stepanova OV, Valikhov MP, Chadin AV, Dvornikov AS, Reshetov IV and Chekhonin VP: Preparation of human olfactory ensheathing cells for the therapy of spinal cord injuries. Bull Exp Biol Med 164: 523-527, 2018.

2. Straley KS, Foo CW and Heilshorn SC: Biomaterial design strategies for the treatment of spinal cord injuries. J Neurotrauma 27: $1-19,2010$.

3. Gu M, Gao Z, Li X, Zhao F, Guo L, Liu J and He X: Feasibility of diffusion tensor imaging for assessing functional recovery in rats with olfactory ensheathing cell transplantation after contusive spinal cord injury (SCI). Med Sci Monit 23: 2961-2971, 2017.

4. Gu M, Gao Z, Li X, Guo L, Lu T, Li Y and He X: Conditioned medium of olfactory ensheathing cells promotes the functional recovery and axonal regeneration after contusive spinal cord injury. Brain Res 1654: 43-54, 2017.

5. Au E and Roskams AJ: Olfactory ensheathing cells of the lamina propria in vivo and in vitro. Glia 41: 224-236, 2003.

6. Khankan RR, Griffis KG, Haggerty-Skeans JR, Zhong H, Roy RR, Edgerton VR and Phelps PE: Olfactory ensheathing cell transplantation after a complete spinal cord transection mediates neuroprotective and immunomodulatory mechanisms to facilitate regeneration. J Neurosci 36: 6269-6286, 2016.

7. FührmannT,Anandakumaran PN and ShoichetMS:Combinatorial therapies after spinal cord injury: How can biomaterials help? Adv Healthc Mater 6, 2017 (doi: 10.1002/adhm.201601130).

8. Zhang Q, Yan S, You R, Kaplan DL, Liu Y, Qu J, Li X, Li M and Wang X: Multichannel silk protein/laminin grafts for spinal cord injury repair. J Biomed Mater Res A 104: 3045-3057, 2016.

9. Zhu S, Ge J, Wang Y, Qi F, Ma T, Wang M, Yang Y, Liu Z, Huang J and Luo Z: A synthetic oxygen carrier-olfactory ensheathing cell composition system for the promotion of sciatic nerve regeneration. Biomaterials 35: 1450-1461, 2014.

10. Kabiri M, Oraee-Yazdani S, Dodel M, Hanaee-Ahvaz H, Soudi S, Seyedjafari E, Salehi M and Soleimani M: Cytocompatibility of a conductive nanofibrous carbon nanotube/poly (L-Lactic acid) composite scaffold intended for nerve tissue engineering. EXCLI J 14: 851-860, 2015

11. Zhou M, Qiao W, Liu Z, Shang T, Qiao T, Mao C and Liu C: Development and in vivo evaluation of small-diameter vascular grafts engineered by outgrowth endothelial cells and electrospun chitosan/poly( $\varepsilon$-caprolactone) nanofibrous scaffolds. Tissue Eng Part A 20: 79-91, 2014.

12. Fan Z, Shen Y, Zhang F, Zuo B, Lu Q, Wu P, Xie Z, Dong Q and Zhang $\mathrm{H}$ : Control of olfactory ensheathing cell behaviors by electrospun silk fibroin fibers. Cell Transplant 22 (Suppl 1): S39-S50, 2013

13. Sofia S, McCarthy MB, Gronowicz G and Kaplan DL: Functionalized silk-based biomaterials for bone formation. J Biomed Mater Res 54: 139-148, 2001.

14. Pavoni E, Tozzi S, Tsukada M and Taddei P: Structural study on methacrylamide-grafted Tussah silk fibroin fibres. Int J Biol Macromol 88: 196-205, 2016.

15. Gao Y, Shao W, Qian W, He J, Zhou Y, Qi K, Wang L, Cui S and Wang R: Biomineralized poly (1-lactic-co-glycolic acid)-tussah silk fibroin nanofiber fabric with hierarchical architecture as a scaffold for bone tissue engineering. Mater Sci Eng C Mater Biol Appl 84: 195-207, 2018.

16. Asakura T, Nishi H, Nagano A, Yoshida A, Nakazawa Y,Kamiya M and Demura M: NMR analysis of the fibronectin cell-adhesive sequence, Arg-Gly-Asp, in a recombinant silk-like protein and a model peptide. Biomacromolecules 12: 3910-3916, 2011.

17. Min BM, Lee G, Kim SH, Nam YS, Lee TS and Park WH: Electrospinning of silk fibroin nanofibers and its effect on the adhesion and spreading of normal human keratinocytes and fibroblasts in vitro. Biomaterials 25: 1289-1297, 2004.

18. Yang F, Murugan R, Wang S and Ramakrishna S: Electrospinning of nano/micro scale poly(L-lactic acid) aligned fibers and their potential in neuronal tissue engineering. Biomaterials 26 : 2603-2610, 2005.

19. Smeal RM, Rabbitt R, Biran R and Tresco PA: Substrate curvature influences the direction of nerve outgrowth. Ann Biomed Eng 33: 376-382, 2005
20. Smeal RM and Tresco PA: The influence of substrate curvature on neurite outgrowth is cell type dependent. Exp Neurol 213: 281-292, 2008

21. Qu J, Wang D, Wang H, Dong Y, Zhang F, Zuo B and Zhang H: Electrospun silk fibroin nanofibers in different diameters support neurite outgrowth and promote astrocyte migration. J Biomed Mater Res A 101: 2667-2678, 2013.

22. Wang J, Ye R, Wei Y, Wang H, Xu X, Zhang F, Qu J, Zuo B and Zhang H: The effects of electrospun TSF nanofiber diameter and alignment on neuronal differentiation of human embryonic stem cells. J Biomed Mater Res A 100: 632-645, 2012.

23. Panda N, Bissoyi A, Pramanik K and Biswas A: Development of novel electrospun nanofibrous scaffold from P. Ricini and A. Mylitta silk fibroin blend with improved surface and biological properties. Mater Sci Eng C Mater Biol Appl 48: 521-532, 2015.

24. Khamhaengpol A and Siri S: Composite electrospun scaffold derived from recombinant fibroin of weaver ant (Oecophylla smaragdina) as cell-substratum. Appl Biochem Biotechnol 183: 110-125, 2010.

25. Yang R, Wu P, Wang X, Liu Z, Zhang C, Shi Y, Zhang F and Zuo B: A novel method to prepare tussah/Bombyx mori silk fibroin-based films. RSC Adv 8: 22069-22077, 2018.

26. Parker J: The protection of laboratory animals: A response to Stephenson. J Med Philos 19: 389-394, 1994.

27. Min BM, Jeong L, Nam YS, Kim JM, Kim JY and Park WH: Formation of silk fibroin matrices with different texture and its cellular response to normal human keratinocytes. Int J Biol Macromol 34: 281-288, 2004.

28. Zhuang Y, Zhang Q, Feng J, Wang N, Xu W and Yang H: The effect of native silk fibroin powder on the physical properties and biocompatibility of biomedical polyurethane membrane. Proc Inst Mech Eng H 231: 337-346, 2017.

29. Qi Y, Wang H, Wei K, Yang Y, Zheng RY, Kim IS and Zhang KQ: A review of structure construction of silk fibroin biomaterials from single structures to multi-level structures. Int J Mol Sci 18: pii: E237, 2017.

30. Zhang W, Chen L, Chen J, Wang L, Gui X, Ran J, Xu G, Zhao H, Zeng M, Ji J, et al: Silk fibroin biomaterial shows safe and effective wound healing in animal models and a randomized controlled clinical trial. Adv Healthc Mater 6, 2017 (doi: 10.1002/adhm.201700121).

31. Fernández-García L, Marí-Buyé N, Barios JA, Madurga R, Elices M, Pérez-Rigueiro J, Ramos M, Guinea GV and González-Nieto D: Safety and tolerability of silk fibroin hydrogels implanted into the mouse brain. Acta Biomater 45: 262-275, 2016.

32. Zhang Z, Yoo R, Wells M, Beebe TP Jr, Biran R and Tresco P: Neurite outgrowth on well-characterized surfaces: Preparation and characterization of chemically and spatially controlled fibronectin and RGD substrates with good bioactivity. Biomaterials 26: 47-61, 2005.

33. Luan XY, Wang Y, Duan X, Duan QY, Li MZ, Lu SZ, Zhang HX and Zhang XG: Attachment and growth of human bone marrow derived mesenchymal stem cells on regenerated antheraea pernyi silk fibroin films. Biomed Mater 1: 181-187, 2006.

34. Minoura N, Aiba S, Gotoh Y, Tsukada M and Imai Y: Attachment and growth of cultured fibroblast cells on silk protein matrices. J Biomed Mater Res 29: 1215-1221, 1995.

35. Shen Y, Qian Y, Zhang H, Zuo B, Lu Z, Fan Z, Zhang P, Zhang $F$ and Zhou C: Guidance of olfactory ensheathing cell growth and migration on electrospun silk fibroin scaffolds. Cell Transplant 19: 147-157, 2010.

36. Aznar-Cervantes S, Pagán A, Martínez JG, Bernabeu-Esclapez A, Otero TF, Meseguer-Olmo L, Paredes JI and Cenis JL: Electrospun silk fibroin scaffolds coated with reduced graphene promote neurite outgrowth of PC-12 cells under electrical stimulation. Mater Sci Eng C Mater Biol Appl 79: 315-325, 2017.

This work is licensed under a Creative Commons Attribution-NonCommercial-NoDerivatives 4.0 International (CC BY-NC-ND 4.0) License. 